\title{
Lâmpada de lava como experimento didático de simulação de plumas mantélicas
}

\author{
LAVA LAMPS AS DIDATIC EXPERIMENT OF MANTLE PLUMES SIMULATION
}

\author{
Raphael Martins Coelho \& Alexandre de Oliveira Chaves \\ Inst. Geoc. UFMG, Av. Antônio Carlos, 6627, Pampulha. 31270-901 Belo Horizonte, MG
}

ABSTRACT: This paper presents the lava lamp as useful didactc material, which allows the experimentation by analogy to demonstrate an important geodynamical process involving the upwelling of mantle plumes in the Earth's lower mantle.

\author{
Manuscrito: \\ Recebido: 17/04/2017 \\ Aceito: 19/07/2017
}

\begin{abstract}
Citation:Coelho R.M. \& Chaves A.0. 2017. Lâmpada de lava como experimento didático de simulação de plumas mantélicas. Terræ Didatica, 12(2):123-126. < http://www.ige.unicamp.br/ terraedidatica/ $>$.
\end{abstract}

Keywords: Mantle plume, lava lamp, experimentation by analogy, Geosciences teaching.

\section{Introdução}

Plumas mantélicas são condutos verticalizados de material rochoso quente, com origem na base do manto inferior, que ascendem para a astenosfera (Morgan 1972). O conceito de plumas mantélicas começou a ser discutido na década de 60 para tentar explicar a incomum cadeia de vulcões do Havaii que se encontra a mais de $3200 \mathrm{~km}$ de distância de bordas de placas, onde normalmente os vulcões são encontrados (Wilson 1963). Desde então, diversos eventos magmáticos têm sido atribuídos à ação de plumas mantélicas (Ernst \& Buchan 2003), como por exemplo, o magmatismo intraplaca (hotspots) e as províncias ígneas gigantes (large igneous provinces - LIP) mundo afora.

No intuito de asseverar a existência de plumas mantélicas, French \& Romanowicz (2015) utilizaram a técnica de imageamento sísmico do manto terrestre, combinando computação acurada com informações contidas no formato de ondas sísmicas tipo-s (shear waves), as quais têm sua velocidade reduzida ao atravessar meios de baixa densidade. A técnica revelou a presença de robustos condutos termoquímicos verticalizados abaixo de importantes hotspots ao redor do mundo (Fig. 1). Os condutos se estendem desde a fronteira manto-núcleo (core mantle boundary - CMB) até $1.000 \mathrm{~km}$ abaixo da superfície terrestre, onde muitos defletem horizontalmente ao entrar na vigorosa circulação do manto superior. $\mathrm{Na}$ base do manto, estes condutos estão enraizados nas chamadas zonas de velocidade sísmica ultra-baixa (ultra-low velocity zones - ULVZ). A correspondência estabelece uma conexão entre tais zonas e plumas mantélicas (McNamara et al. 2010, Cottaar \& Romanowicz 2012, Thorne et al. 2013).

O conduto observado na figura $1 \mathrm{~A}$ se assemelha àquele formado durante o funcionamento de uma lâmpada de lava. Lâmpada de Lava (figura 2) é uma lâmpada decorativa que contém dois líquidos insolúveis entre si, produzindo um efeito que lembra lava. O funcionamento deste dispositivo é bem simples, utilizando o princípio de que os materiais mudam de densidade com o aumento de temperatura.

Dois líquidos, A e B, de densidades semelhantes, sendo o líquido A ligeiramente mais denso que o líquido $B$, são colocados em um aparato de maneira que o líquido A possa ser aquecido. À medida que o líquido A se aquece, este vai se tornando menos denso e começa a ascender e atravessar o líquido $B$.

Este trabalho tem como objetivo apresentar a lâmpada de lava como valioso material didático para a compreensão de importantes processos da 


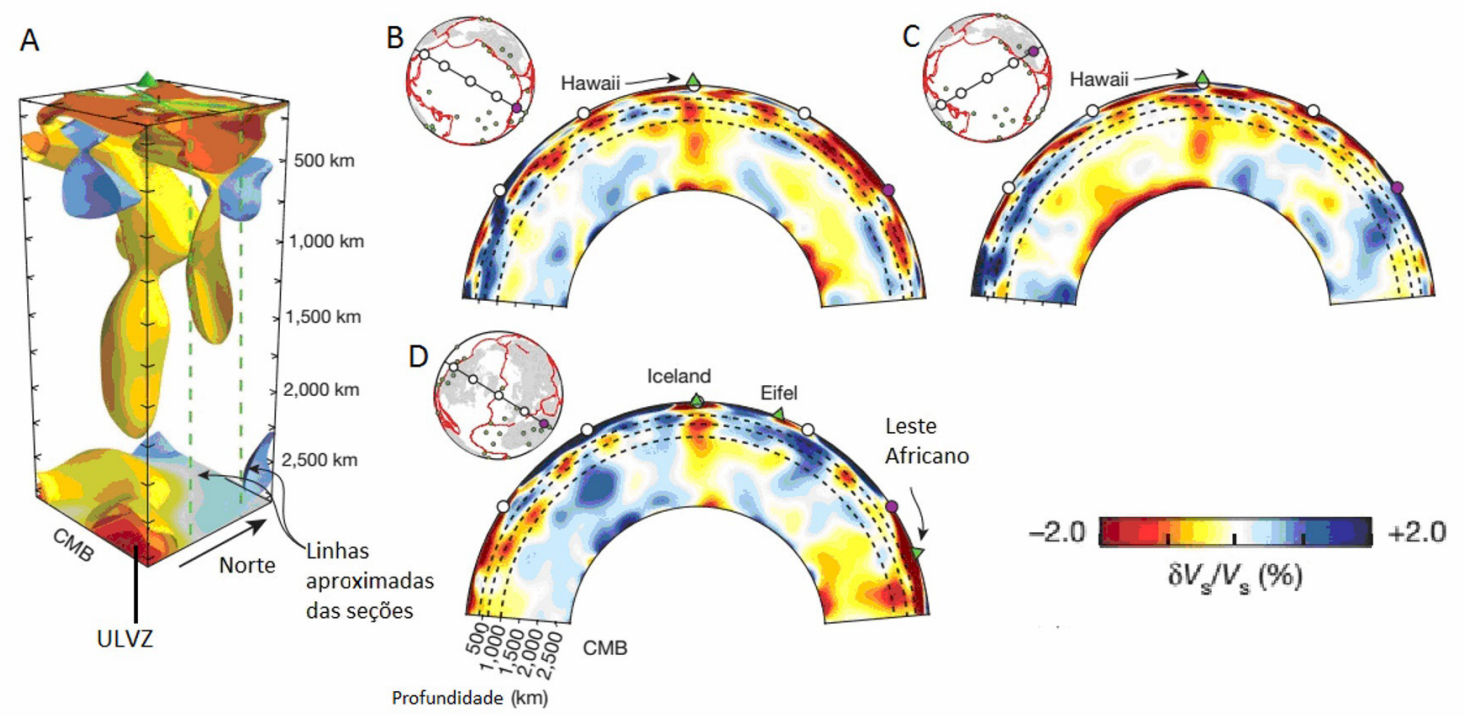

Figura 1. A - Estrutura tridimensional da pluma do Hawaii vista a partir do sudeste. B e C - seções bidimensionais passando pelo Hawaii, cujos planos estão representados no topo da figura $1 \mathrm{~A}$. D - seção mostrando uma pluma sob a Islândia e outra sob o Leste Africano. CMB: Core-Mantle Boundary ou Fronteira Manto-Nucleo. ULVZ: Ultra-Low Velocity Zone ou Zona de Velocidade Sísmica Ultra-Baixa. Extraído de French \& Romanowicz (2015).

geodinâmica terrestre envolvendo a ascensão de plumas mantélicas no manto inferior da Terra, cuja existência parece confirmada por French \& Romanowicz (2015).

\section{Materiais e métodos}

Para a montagem da lâmpada de lava optou se por materiais ambientalmente sustentáveis, fazendo o reaproveitamento de metais de sucata reciclada para a confecção da base e o pote de vidro de palmito.

Materiais utilizados:

1 pote de vidro de palmito de $2,5 \mathrm{~kg}$

Água

Óleo de soja

Álcool $94^{\circ} \mathrm{GL}$

1 lâmpada halógena de 150 watts

Base de metal

Ligação elétrica dimerizável

Béquer de $500 \mathrm{ml}$

Bastão de vidro

A base de apoio é feita por meio da soldagem das hastes de metal recicladas e devidamente cortadas para que o pote de palmito se encaixe perfeitamente. Esta base é parafusada em uma prancha de madeira que recebe a montagem da parte elétrica e suporte para a lâmpada halógena. A lâmpada é ligada por fios a um dimer, dispositivo de controle de potência de equipamentos elétricos, para que se possa controlar a intensidade luminosa da lâmpada, que atua também como fonte de calor. A base montada pode ser observada na figura 3 .

A parte mais importante da montagem do equipamento é o acerto da densidade da mistura água + álcool com a densidade do óleo de soja, de modo que a densidade mistura $\approx$ densidade $_{\text {oleo }}$, destacando que a densidade ${ }_{\text {óleo }}$ precisa ser ligeiramente maior que a densidade $e_{\text {mistura. }}$ De início, deve-se colocar em um Béquer de $500 \mathrm{ml}$ uma parte de água e três partes de álcool. Para se averiguar a correta densidade da mistura, adiciona-se uma pequena gota de óleo à mistura. Se a densidade estiver correta, a gota de óleo deve ficar praticamente imóvel no interior da mistura e afundar muito lentamente. Se a gota flutuar totalmente, deve-se adicionar mais álcool aos poucos e agitar a mistura lentamente. Se a gota afundar muito rapidamente deve se adicionar um pouco de água. Em ambos os casos, a mistura deve

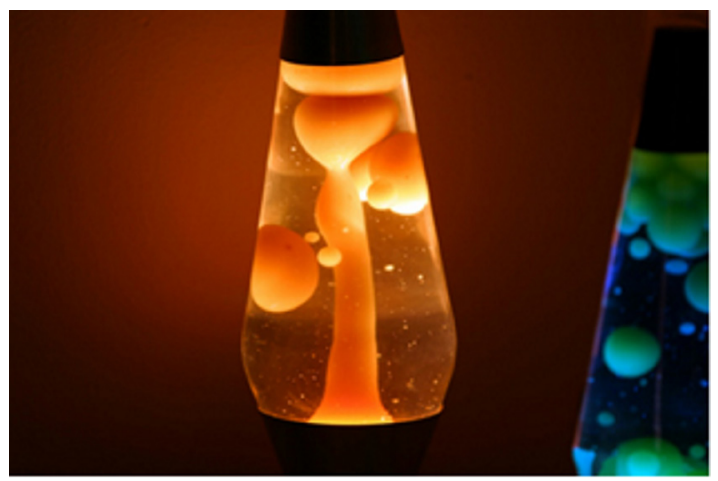

Figura 2. Lâmpada de lava vendida comercialmente (fonte: Brasil Escola) 


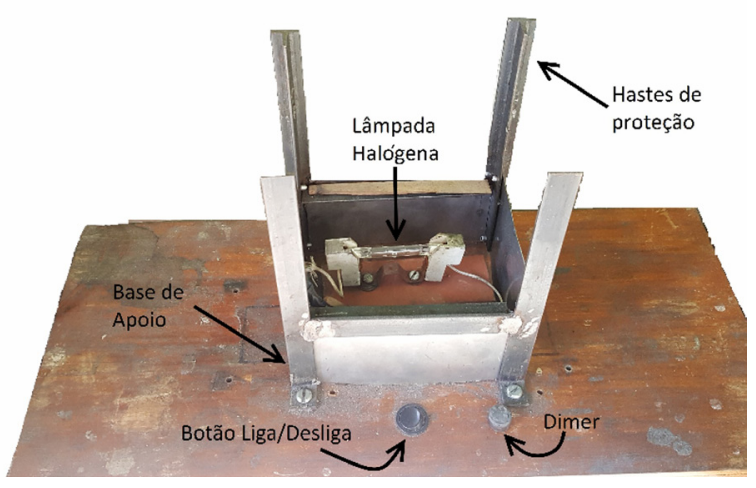

Figura 3. Montagem da base metálica (sem o vidro de palmito) e dos equipamentos elétricos

descansar por alguns minutos. Como a adição de álcool torna o óleo ligeiramente solúvel na mistura, não é recomendada a agitação vigorosa após o acréscimo das gotas de óleo, pois a mistura pode se tornar turva.

Com o domínio das proporções de líquidos a serem usadas, adiciona-se ao vidro de palmito 2,3 litros de mistura água + álcool. Escorrendo em um bastão de vidro, deve-se adicionar vagarosamente $900 \mathrm{ml}$ de óleo de soja. Este cuidado deve ser tomado para que não se formem gotículas de óleo que ficarão em suspensão por diversas horas. $O$ vidro deve ser bem tampado para que não haja perda de líquidos por evaporação e o sistema deve descansar até que todo óleo assente no fundo do pote. Em seguida, o vidro é colocado sobre a base conforme observado na figura 4.

\section{Resultados}

Após alguns segundos de aquecimento, observa se o primeiro ciclo de ascensão de material (Fig. 5). Recomenda-se diminuir a potência da lâmpada girando a chave do dimer para que a ascensão do material seja mais lenta e desta forma o ciclos sejam mais sustentáveis.

Conforme mostrado na figura 5, quando o óleo é aquecido, ocorre a formação de condutos ascendentes tubiformes que partem da região mais aquecida do pote, que é a sua base, em direção à parte menos aquecida, que é seu topo. A "cabeça" do conduto vertical se desprende de sua "calda" formando uma grande gota que flutua na mistura por alguns minutos. Após este tempo, a gota esfria e afunda para se misturar ao óleo da base, refazendo o ciclo quando este é novamente aquecido pela lâmpada.

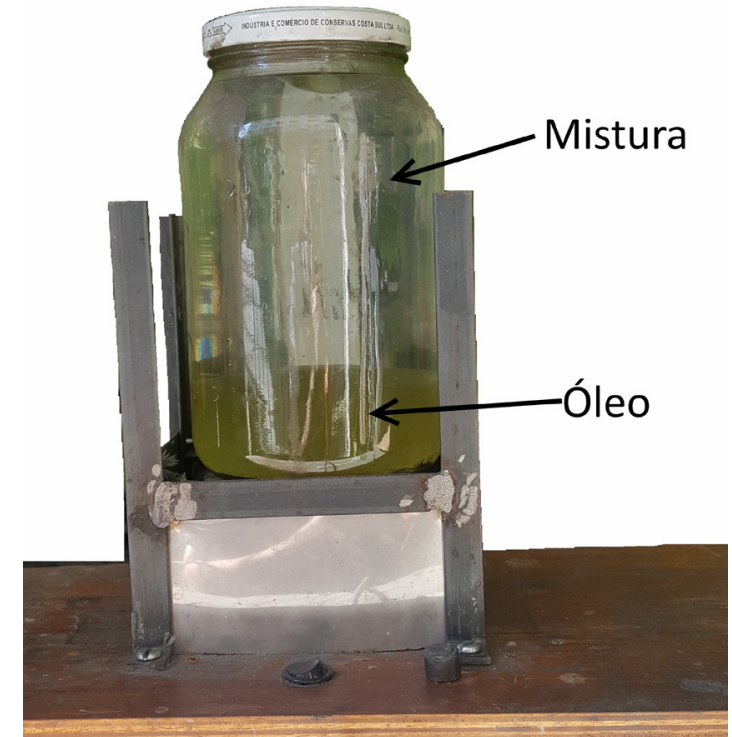

Figura 4. Montagem da base metálica com o vidro de palmito e equipamentos elétricos

\section{Considerações Finais}

O professor ou divulgador ao utilizar este equipamento com a intenção de mostrar sua analogia com processos mantélicos naturais, deve, antes de tudo, estar consciente dos objetivos de aprendizagem pretendidos. O professor deve ressaltar que o manto é sólido e deve ser enfático ao mostrar que os líquidos envolvidos na demonstração são apenas para reproduzir uma dinâmica que leva milhões de anos para se processar, envolvendo materiais sólidos aquecidos e ascendentes. Outro aspecto que pode gerar dúvida, pois é recorrente no imaginário popular, e deverá ser esclarecido, é que apesar do nome do equipamento ser "lâmpada de lava", não há lava fluindo pelo manto da Terra. A lava que sai nos vulcões situados sobre plumas mantélicas é normalmente proveniente de processos de fusão por descompressão do material rochoso ascendente.

Com este experimento simples, é possível facilitar a visualização de um processo geodinâmico importante. Comparando-se os movimentos observados na lâmpada de lava apresentada neste trabalho com a imagem computacional gerada pelo levantamento sísmico de French \& Romanowicz (2015), é possível inferir que o movimento do material na porção inferior do manto terrestre realmente se assemelha aos condutos verticalizados de uma lâmpada de lava em funcionamento.

A experimentação analógica aqui utilizada permite ao educador preparar uma aula de Geodinâmica 


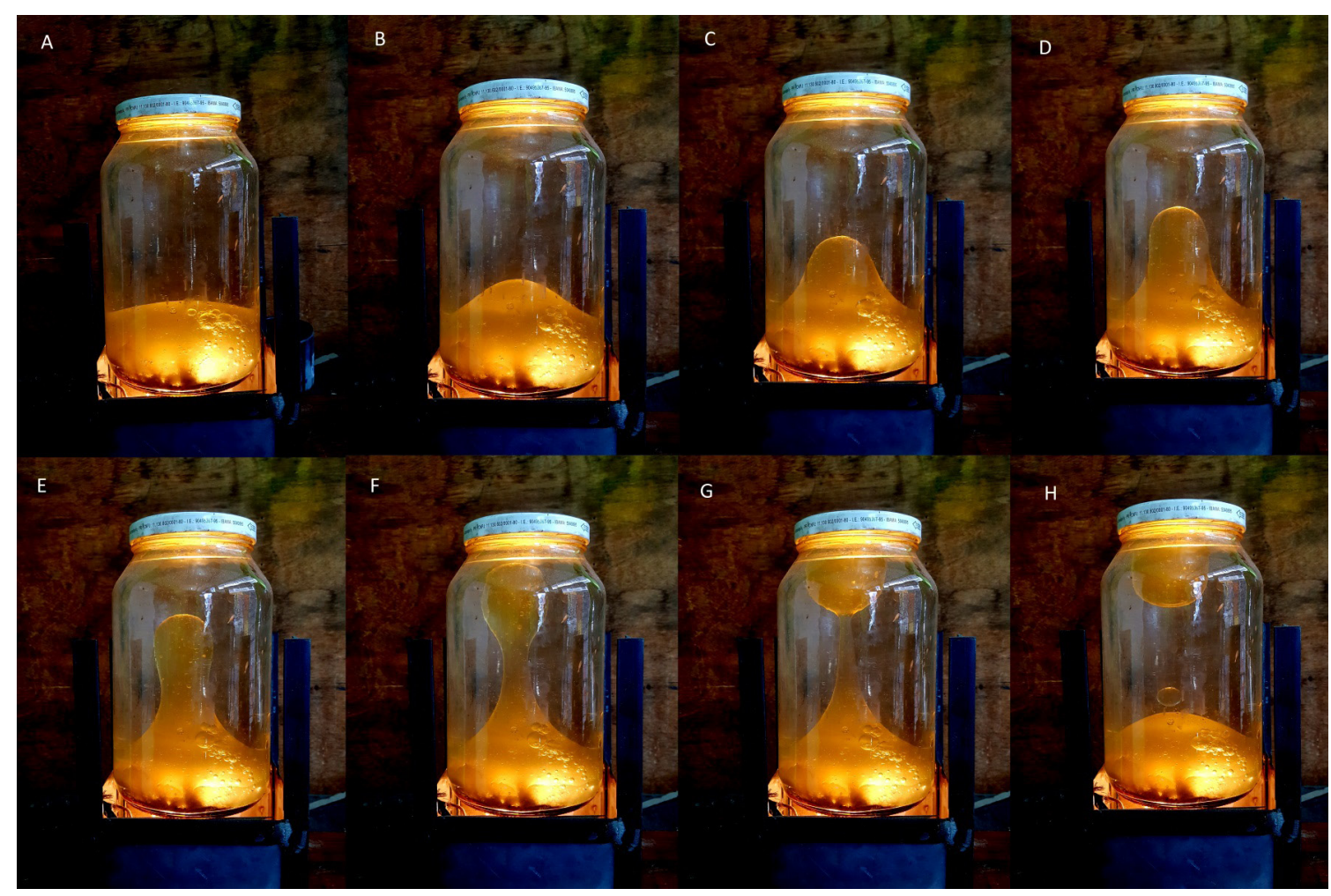

Figura 5. Sequência de formação de condutos tubiformes ascendentes após alguns minutos de aquecimento do sistema, sendo A o início do processo e $\mathrm{H}$ o final do processo

que aborda a noção da lenta e permanente atividade de plumas mantélicas, que leva ao questionamento e debate sobre uma série de conceitos como configuração interna da terra, movimentos de convecção, fatores relativos à formação de magmas e hotspots, tendo em vista a vigorosa circulação horizontal de material rochoso no manto superior, conforme também atestado por French \& Romanowicz (2015).

\section{Referências}

Brasil Escola - Fazendo uma lâmpada de lava. URL: http://educador.brasilescola.uol.com.br/ estrategias-ensino/fazendo-uma-lampada-lava.htm Acesso 17/03/2017.

Cottaar S., Romanowicz B. 2012. An unusually large ULVZ at the base of the mantle near Hawaii. Earth
Planet. Sci. Letters, 355-356:213-222.

Ernst R E., Buchan K.L. 2003. Recognizing mantle plumes in the geological record. Ann. Rev. Earth Planet. Sci., 31:469-523.

French S.W., Romanowicz B.A. 2015. Broad plumes rooted at the base of the Earth's mantle beneath major hotspots. Nature, 525:95-99. doi:10.1038/ nature 14876

McNamara A.K., Garnero E.J., Rost S. 2010. Tracking deep mantle reservoirs with ultra-low -velocity zones. Earth Planet. Sci. Letters, 299:1-9.

Morgan W.J. 1972. Plate motions and deep mantle convection. Geol. Soc. Am. Bull., 132:7-22.

Thorne M.S., Garnero E.J., Jahnke G., Igel H. McNamara A. 2013. Mega ultra-low velocity zone and mantle flow. Earth Planet. Sci. Letters, 364:59-67.

Wilson J.T. 1963. A possible origin of the Hawaiian Islands. Can. J. Earth Sci., 41:863-870.

Resumo: Este trabalho apresenta a lâmpada de lava como valioso material didático que permite a experimentação analógica para ilustrar importante processo geodinâmico que envolve a ascensão de plumas mantélicas no manto inferior da Terra.

PALAVRAS-CHAVE: Pluma mantélica, lâmpada de lava, experimentação analógica, ensino de Geociências. 